\title{
Conception and sizing of an industrial waste water treatment station equipped with biogas digester, UV reactor and reverse osmosis unit
}

\author{
Elmissaoui $\mathrm{S}^{1}$, Sellami $\mathrm{MH}^{1,2^{*}}$, Taher $\mathrm{O}^{1}$
}

\author{
${ }^{1}$ Laboratory of soft material and electromagnetic modelling, Physics Department, FST, University Tunis El Manar \\ ${ }^{2}$ High School of Engineering Medjez El Bab, IRESA, Jendouba University, Tunisia \\ *Corresponding Author \\ ORCID ID: 0000-0003-2019-4423
}

\begin{abstract}
The reuse of the treated waste water in all fields (agricultural, industrial, domestic) is an orientation asked by all intervening parties in the water sector in the purpose to protect the environment and combat the scarcity of water resources. This valorization cannot be done without making the appropriate treatment in order to respect the norms. In this work, we are developing a general method to conceptualize a treatment station equipped with biogas digester, UV reactor and Reverse Osmosis (RO) unit. The modeling approach developed permits to test and to ameliorate the efficiency of each cited technique. The main basic equations used are those of Maxwell, mass transfer, radiation transfer and energetic transfer. We have made an analytical resolution of those equations and we have expressed the necessary formulas for the design of each technique. Results from case studies were presented.
\end{abstract}

Keywords - Wastewater valorization, Biogas digester, UV reactor, Reverse Osmosis.

\section{INTRODUCTION}

Actually, at international level, the scarcity of water resources becomes a real problem threatening human wellbeing and humanity developing. That's why, valorising the unconventional water resources (waste water, salt water, sea water), in all sectors of human activities, becomes a priority and an orientation of many countries.

After adequate treatments the use of wastewater is considered as an important additional water resource which could be of great interest to several sectors especially in countries with a semiarid climate. Also, the reuse of waste water after treatment can protect the environment from their reject in their raw state. However, the use of such water without an adequate advanced treatment can affect human health, plants, soils conditions and the underlying groundwater. Introducing the membrane technique like reverse osmosis in the treatment chain and disinfections of wastewater by U.V irradiation are considered as a credible alternative to chemical disinfections because of the absence of toxic products. The functioning of every device in the waste water treatment chain needs an important amount of energy. Reason why introducing, in the treatment chain, a biogas digester producing energy from the extracted sludge can offer the needed energy for the running of the waste water treatment station.

In this work, to respond to requests asked by all intervening in the non-conventional water resources, we are developing a global model permitting to conceptualize a waste water treatment plant equipped with advanced treatment technologies (UV reactor, Biogas digester, Reverse Osmosis unit), to size each device/unit and to test its efficiency. The main basic equations used are those for mass transfer, radiation transfer, energetic transfer and Maxwell. A case study for the waste water issued from a yeast industry installed in Tunisia will be detailed.

\section{THEORETICAL BACKGROUND}

As we said above, valorizing the waste water in different sectors for all human activities, necessitates a high level treatment techniques characterized by an advanced efficiency rate. To elaborate a model permitting to make an efficient conception of each technique, we have to consider the physical phenomena that take place inside. In fact, for the reverse osmosis unit, we consider the membrane as a polarizer that diffracts particles to eliminate 
by polarizing their electric and magnetic fields. So the efficiency and the size, of the membrane depend on its electromagnetic properties, on the hydraulic flow through it and on the amount of electric-magnetic fields exchanged (Elmissaoui et al 2020submitted). The UV reactor, serves to deactivate microorganisms (microbes, bacteria, viruses...) by contact with a UV radiation field emitted by a UV lamp. The UV radiations spread in a hemispherical angle so they touch all the permanent flow of wastewater passing through the reaction medium. Analysing the efficiency of a U.V photon reactor and sizing all its components are needed to specify the amount of radiation used to achieve total or partial destruction of microorganisms and to quantify the hydraulic flow. To realise this goal, we have to determine the UV incident radiation profiles and local volumetric rate of energy absorption profiles (LVREA), both as a function of the spatial position inside the reactor.

For the bio-digester, we will model and conceptualize a biogas reactor that permits both to produce methane from the extracted biomass (sludge from treated wastewater) and to cogenerate from it an important amount of energy as electricity and heat. Knowing that one cubic meter of biogas $\left(60 \% \mathrm{CH}_{4}, 40 \% \mathrm{CO}_{2}\right)$ can give heating value as 20 $25 \mathrm{MJ}$ which corresponds to about half a liter of diesel oil (with a calorific value of about $6 \mathrm{kw} / \mathrm{m}^{3}$ ).

We will apply principally the Maxwell equations, the radiation transfer equations, the mass balance equations and the energy balance equations.

\section{BASIC EQUATIONS FOR THE THREE COMPARTMENTS OF THE MODELING APPROACH}

\subsection{Modeling approach for the reverse osmosis compartment}

Because of its elctromagmetic properties, the particle in its displacement inside the waste water was treated as a wave that interferes with the others waves representing the rest of particles in the wastewater (Elmissaoui et al submitted 2020). The filtering membrane is considered as a polarizer that will polarize the electromagnetic field of every component in the wastewater. The capacity of a membrane to eliminate particles that the end user of the treated wastewater doesn't tolerate is directly linked to the electromagnetic fields of the transmitted and reflected waves of every particle through the membrane. By applying the Maxwell equation and the continuity equation we have expressed the electric and magnetic field of every particle in the wastewater (Haralambos 1998, Hiroyuki T.2001, Karine et al 2017, Kiselyov et al 2019,).
The incident electric field $\left(E_{x, \text { inc }}^{\text {par, }}, E_{y, \text { inc }}^{\text {par }, m}, E_{z, \text { inc }}^{\text {par,m }}\right)$ in respectively the three directions (ox, oy, oz) and for each particles $\mathrm{m}$ (par, $\mathrm{m}$ ) in the wastewater can be expressed as follow:

$$
\begin{aligned}
& E_{x, i n c}^{\text {par, } m}=A_{\mathrm{V}} \cos \theta_{i n c}^{\text {par, } m} e^{i k_{1}^{\text {par }, m_{r}}} \\
& E_{y, i n c}^{\text {par,m }}=A_{h} e^{i k_{1}^{\text {par }, m} r} \\
& E_{z, i n c}^{\text {par } m}=A_{\mathrm{V}} \sin \theta_{i n c}^{\text {par }, m} e^{i k_{1}^{\text {par,m}} r}
\end{aligned}
$$

The reflected electric field, $\left(E_{x, r e f}^{\text {par, } m}, E_{y, r e f}^{\text {par, } m}, E_{z, r e f}^{\text {par, } m}\right)$ for each particle $\mathrm{m}$ in the wastewater for the three direction (ox, oy, oz) :

$$
\begin{gathered}
E_{x, r e f}^{\text {par } m}=B_{v} \cos \theta_{r e f}^{\text {par }, m} e^{i k_{1}^{\text {par }, m} r} \\
E_{y, r e f}^{\text {par,m }}=B_{h} e^{i k_{1}^{\text {par }, m} r} \\
E_{z, r e f}^{\text {par }, m}=B_{\mathrm{v}} \sin \theta_{r e f}^{\text {par }, m} e^{i k_{1}^{\text {par }, m_{r}}}
\end{gathered}
$$

The transmitted electric field, $\left(E_{x, t r a}^{\text {par }, m}, E_{y, t r a}^{\text {par, }}, E_{z, t r a}^{\text {par }, m}\right)$ for each particle $m$ in the wastewater for the three direction (ox, oy, oz) is expressed by :

$$
\begin{gathered}
E_{x, t r a}^{\text {par }, m}=C_{v} \cos \theta_{\text {tra }}^{\text {par }, m} e^{i k_{2}^{\text {par }, m} r} \\
E_{y, t r a}^{\text {par,m }}=C_{h} e^{i k_{2}^{\text {par }, m} r} \\
E_{z, t r a}^{\text {par,m }}=C_{\mathrm{V}} \sin \theta_{\text {tra }}^{\text {par }, m} e^{i k_{2}^{\text {par,m}} r}
\end{gathered}
$$

The incident magnetic field in unity of magnetic excitation $\left(H_{x, \text { inc }}^{\text {par } m}, H_{y, \text { inc }}^{\text {par } m}, H_{z, \text { inc }}^{\text {par, }}\right)$ in respectively the three directions (ox, oy, oz) and for each particles $m$ (par, $\mathrm{m}$ ) in the wastewater can be expressed as follow:

$$
\begin{gathered}
H_{x, i n c}^{\text {par, }}=\mathrm{v}_{\varphi 1} \varepsilon_{1} A_{h} \cos \theta_{i n c}^{\text {par }, m} e^{i k_{1}^{\text {par }, m} r} \\
H_{y, \text { inc }}^{\text {par, } m}=-\mathrm{v}_{\varphi 1} \varepsilon_{1} A_{v} e^{i k_{1}^{\text {par } m} r} \\
H_{z, \text { inc }}^{\text {par, }}=\mathrm{v}_{\varphi 1} \varepsilon_{1} A_{h} \sin \theta_{i n c}^{\text {par }, m} e^{i k_{1}^{\text {par }, m_{r}}}
\end{gathered}
$$

\subsection{Modeling approach for the UV reactor compartment}

In this part, we have proposed equations to predict the distribution of UV radiation inside an open channel photoreactor (used to purify a secondary waste water) in the absence of dispersion effects ( reflections and refractions) and as a function of the spatial coordinates of the system. By solving the radiation transfer equation we have expressed the radiation flux density and the local volumetric rate of energy absorption profiles (LVREA) at any point inside the open channel reactor(Santarelli 1983, Alfano et al 1986, Lopez and Semel. 1999, Sellami et al 2003). The system parameters for the radiation transfer 
equation were taken from experimental measurements (Moreno et al 1997, Tosa and Hirata 1999, Abdennaceur et al 2000, Sellami et al 2003, Sellami et al 2019).

The equation obtained may be formally integrated from a point of entrance at the interior reactor wall $\left(\mathrm{X}=\mathrm{X}_{\mathrm{k}}\right)$ to the point under consideration ( $\mathrm{X}=\mathrm{x}$ ) to give the following expression for the incident UV radiation at any position inside the reactor:

$$
I_{v}(x, \theta, \Phi, t)=I_{0, v}(\theta, \Phi, \mathrm{t}) \exp \left[-\int_{\bar{S}=S R}^{\bar{S}} K_{v}(\bar{S}, t) d \bar{S}\right]
$$

$I_{\Omega, v}$ is the spectral specific intensity of radiation having a frequency $v$ and a direction of propagation $\Omega$ at position $S$ and time t. The spectral volumetric absorption terms is $K_{v}$.

In the most general case, radiation may be arriving at a point inside the media from all direction in space. This radiation must be absorbed by a material point in space containing the different sorts of bacteria (an elementary reacting volume). Consequently, the amount of spectral incident radiation really used to eliminate the bacteria is given by an integration over the solid angle $\Omega$ for all possible situations. The spectral local volumetric rate of energy absorption (LVREA) is formulated by an integral of all the radiation attenuations over the space of reaction and it was given by (Lopez and Semel. 1999, Sellami et al 2003):

$$
\begin{gathered}
e_{v}^{a}(x, t)=K v(r, t) \int_{\Phi_{1}}^{\Phi_{2}} d \Phi \int_{\theta_{1}}^{\theta_{2}} d \theta \sin \theta I_{0, v}(\theta, \Phi, t) \\
* \exp \left[-\int_{\bar{S}=S R}^{\bar{S}} K_{v}(\bar{S}, t) d \bar{S}\right]
\end{gathered}
$$

Hence, we can say that the local volumetric rate of energy absorption LVREA $\left(\mathrm{e}_{v}{ }^{\mathrm{a}}\right)$, represents the amount of photons (in units of energy for a given frequency interval) that are absorbed per unit time and unit reaction volume. So it can be defined as the rate of radiant energy absorbed by particles and it permits to determine the absorption efficiency of our reactor. Hence, knowledge of the LVREA spatial distribution is a key variable for photocatalytic reactor design.

\subsection{Modeling approach for the biogas digester compartment}

In this part by applying conservation equations of mass, energy and motion we have formulated the pressure at any point inside the open channel UV reactor, the optimal hydraulic and biomass retention times, the amount of methane extracted from the biomass produced and finally the sizing parameter of the reactor (volume, surface, length , depth, height...)

\subsubsection{Hydraulic modeling of the biogas digester}

The hydraulic pressure inside is determined by applying the Bernoulli theorem between the entering point and any position in the reactor (Sellami and Marzouk 2013, Sellami2015). We can express it by:

$$
\sum_{i} \mathrm{H}_{\mathrm{i}}=\sum_{\mathrm{i}} \mathrm{H}_{\mathrm{i}+1}+\sum_{\mathrm{i}} \mathrm{j}_{\text {lin, } \mathrm{i}} \mathrm{L}_{\mathrm{i}}+\sum_{\mathrm{k}} \mathrm{J}_{\text {sing, } \mathrm{k}}
$$

$\mathrm{H}_{\mathrm{i}}$ : The total charge or pressure at the knot $\mathrm{i}, j_{\text {lin }, i}$ : The linear loss of pressure at the section i, $L_{i}$ : The length of the section $\mathrm{i}, J_{\text {sing, }}$ : The singular loss of energy in the knot $\mathrm{k}$ The total charge at any section i inside the installation is formulated by:

$$
H_{i}=Z_{i}+\frac{P_{i}}{\rho g}+\frac{V_{i}^{2}}{2 g}
$$

$Z_{i}$ : Altitude of the point I, $P_{i}$ : Pressure at the point I, $V_{i}$ : Speed of the flux at the point I, g: Gravity acceleration, $\rho$ : Volume mass

There are many formulas that express the linear and singular loss of energy and they depend on the roughness of the inner side of the accessories through which the sludge passes and the kind of singularity. They can be represented by the following general forms:

$$
\begin{gathered}
J_{\text {sing }}=\varepsilon \frac{V^{2}}{2 g} \\
j_{\text {lin }}=\beta Q^{n} D^{m}
\end{gathered}
$$

$\mathrm{Q}$ : Debit of the waste water, D: Diameter of the tube, $\beta$ : Coefficient of roughness for the linear loss of energy, $\varepsilon$ : Coefficient of singularity, V: Speed of the water flux, n, m: Coefficients characterizing the fluid and the installation

Then we can formulate the hydraulic retention time $\left(\mathrm{H}_{\mathrm{RT}}\right)$ by:

$$
\mathrm{H}_{\mathrm{RT}}=\frac{\mathrm{Vol}_{\mathrm{dig}}}{\mathrm{Q}_{\mathrm{eff}}}
$$

$H_{R T}$ : Hydraulic retention time, $V_{\text {olig }}$ :Volume of the digester, $Q_{\text {eff }}$ : Debit of the effluent

This parameter $\left(H_{R T}\right)$ gives an indication about the optimal time during which we keep the biomass inside the reactor in order to produce an important amount of biogas in a short period (Gasparikova et al 2005, Venkatesh et al 2013). We define also the biomass retention time $\left(B_{R T}\right)$ :

$$
B_{R T}=\frac{V o l_{d i g} A_{b-d i g}}{Q_{e f f} A_{b-e f f}}
$$


$A_{b-d i g}:$ Amount of the biomass in the digester, $A_{b-e f f}$ : Amount of the biomass in the effluent, The time of rest inside the reactor in order optimize its efficiency is:

$$
t_{\text {rest }}=\left(\frac{\tau_{g r M_{n d C D O}}}{F_{\frac{1}{2} s p}+M_{n d C D O}}-F_{d e c}\right)^{-1}
$$

$t_{\text {rest }}$ : Time of rest (day), $\tau_{g r}$ : Rate of growt $(g / g d a y)$, $M_{n d-C D O}$ : Mass of non-degradablechemical demand in oxygen $\left(g / m^{3}\right) F_{d e c}$ :Decadence factor $(g / g d a y), F_{1 / 2 s p}$ : Factor of half the speed $(\mathrm{mg} / \mathrm{l})$

The biogas produced is collected at the superior part of the digester and the optimization of the amount collected depends on three principal factors: the composition of the substrate, the time of rest and the temperature inside the digester. To increase the efficiency of the reactor we must propose the size that permits to have equality between the hydraulic retention time and the biomass retention time (Azimi and Zamanzadeh 2004, Banu et al 2007).

\subsection{2 . Energetic modeling for the biogas digester:}

To model the energetic process inside a digester we must consider the amount of methane to have inside the biogas disengaged, That amount of biogas released is directly related to the quantity of biomass to restrict from the waste water. The amount of biomass produced is expressed by the following equation (Sellami and Marzouk 2013, Lise et al 2008, Mogens et al 2008, Arsova 2010):

$$
\begin{aligned}
B_{\text {pro }}=1,176 & t_{\text {rest }} B_{\text {deb }} F_{\text {dec }}\left(\frac{Y_{\text {bio }}\left(M_{\text {ndCDO }}-M_{i-C D O}\right)}{1+T_{\text {rest }} F_{\text {dec }}}\right) \\
& +Q_{\text {eff }}\left(M_{\text {sus }}-M_{\text {vol }}\right)
\end{aligned}
$$

$Q_{\text {eff }}:$ Debit of the effluent $\frac{m^{3}}{j}, Y_{\text {bio }}:$ Biomass yiel $\frac{g r}{g r}, M_{i-C D C O}$ : Initial mass of the chemical demand of oxygen $\frac{g r}{m^{3}}, M_{n d C D O}$ :Mass of the non-degradable chemical demand of oxygen, $\frac{g r}{m^{3}}, B_{d e b}$ : Biomass fraction as debris $\left(\frac{g r}{g r}\right), M_{\text {sus }}$ : Mass of suspended matter $\frac{g r}{m^{3}}, M_{v o l}$ : Mass of volatile suspended matter $\mathrm{gr} / \mathrm{m}^{3}$

The amount of methane produced is estimated by:

$$
A_{\text {meth-prod }}=R_{\text {meth }}\left(M_{i-C D O}-M_{n d C D O}\right) Q_{\text {eff }}
$$

$R_{\text {meth }}:$ Rate of methane produced

The amount of energy produced is formulated by:

$$
E_{\text {tot-prod }}=A_{\text {meth-prod }} D_{\text {meth }} E_{\text {prod } / \text { gr-meth }}
$$

$E_{\text {tot-prod }}$ : Total energy produced, $A_{\text {meth-prod }}$ : Amount of methane produced, $D_{\text {meth }}$ :Methane density, $E_{\text {prod/gr-meth }}:$ Energy produced per gram of methane

Generally we consider that $95 \%$ of the energy restituted from the biogas could be valorized then we can write:

$$
E_{\text {val }}=0,95 \mathrm{E}_{\text {tot-prod }}
$$

\section{$E_{\text {val }}:$ Valorized energy}

From the amount of energy we can valorize we must consider the needed energy for the boiler to heat the mud which is generally evaluated at about $30 \%$ from that valorized and the pumping energy. We noticed them by auxiliary energy and we can write:

$$
\begin{aligned}
& E_{a u x} \\
& =0,3 \frac{E_{\text {val }}}{Y_{b}} \\
& +\frac{\rho g Q_{\text {eff }}\left(\sum_{i} J_{\text {sing }, i}+\sum_{j} J_{\text {lin }, j} L_{i-i+1}+\sum_{i} \Delta z_{i, i+1}\right)}{Y_{t} Y_{m}}
\end{aligned}
$$

$E_{\text {aux }}$ : Auxiliary energy, $Y_{b}$ : yield of the boiler, $Y_{t}$ : Yield of the turbine, $Y_{m}$ : Yield of the motor, $J_{\sin , i}$ : Singular loss of energy in the knot I, $J_{\text {lin }, j}$ :Linear loss of energy for the section $\mathrm{j}$ between two successive knots, $L_{i-i+1}$ : Distance between two successive knots, $\Delta z_{i, i+1}$ : Difference of altitude between the knots $i$ and $i+1$

The loss of energy through the repartitions of the digester can be by convection and by conduction. Then the total loss of energy can be formulated as follow:

$$
E_{\text {lost }, \text { rep }}=t\left[\sum_{k} S_{k} U_{k} \Delta T_{k}+\sum_{l} \operatorname{Vol}_{\text {lim }, l} C_{l} \Delta T_{l}\right]
$$

$E_{\text {lost,rep }}$ :Total loss of energy through the repartitions of the digester, $\mathrm{t}$ : Time

$S_{k}$ : Surface of the repartition $\mathrm{k}, U_{k}$ :Coefficient of conductivity of the repartition $\mathrm{k},, \Delta T_{k}$ : Difference of temperature between the repartition $\mathrm{k}$ and the exterior, $V_{\text {olim }, l}$ : Limited Volume inside the digester, $C_{l}$ : Thermal volumetric capacity of the fluid in the limited volume inside the digester, $\Delta T_{l}$ : Difference of temperature between the limited volume and the exterior

The energetic balance for the digester can then be written as follow:

$$
E_{\text {rec }}=E_{\text {val }}-E_{\text {aux }}-E_{\text {lost }, \text { rep }}
$$

$E_{\text {rec }}$ : Recovered energy, $E_{\text {val }}$ : Valorized energy, $E_{\text {aux }}$ : Auxiliary energy, $E_{\text {lost }, \text { rep }}$ : Lost of energy by repartition 


\subsubsection{Modeling for the assessment of the reactor size's}

Generally to define the optimal size of a biogas reactor we need to know the quantity of biomass to attract from the waste water, the amount of biogas to produce and our real need from energy (heat or electric form). After, as many authors (Lettinga and Hulshoff 1991, Lew et al 2004), we will use simple formulas linking the input parameters characterizing the waste water flux and the sizes of the reactor to make the optimal conceptualization.

The total volume of the liquid for the acceptable organic charge inside the reactor is expressed by (Duncan .M 2004, Mogens et al 2008):

$$
V o l_{\text {liq-tot }}=\frac{1}{F_{e}} \frac{M_{i-C D O} Q_{\text {eff }}}{\tau_{\text {org }}}
$$

$V_{\text {liq-tot }}$ : Total volume of the liquid in the reactor $\left(\mathrm{m}^{3}\right)$, $\tau_{\text {org }}$ : Rate of organic charge $\left.\mathrm{kg} / \mathrm{m}^{3}\right), F_{e}$ :Factor of efficiency

For the transversal surface of the reactor it can be estimated from the following usual formula:

$$
S_{\text {trans-reac }}=\frac{Q_{\text {eff }}}{V_{\text {sp,asc }}}
$$

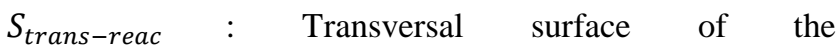
reactor $\left(m^{2}\right), \mathrm{V}_{\mathrm{sp}, \text { asc }}$ : Velocity of the ascendant flux $(\mathrm{m} / \mathrm{h})$

The height of the liquid in the digester is calculated:

$$
H_{\text {liq-dig }}=\frac{\operatorname{Vol}_{\text {liq-tot }}}{S_{\text {trans-reac }}}+\frac{\text { Vol }_{\text {gaz-pro }}}{S_{\text {dir }}}
$$

Vol ${ }_{\text {gaz-pro }}$ : Volume of gaz produced, $S_{d i r}:$ Direct surface of the section

\section{RESULTS AND DISCUSSION}

In an advanced waste water treatment station, the waste waters have to pass respectively through many preliminary treatment techniques placed in chain representing the pretreatment phase. After, when the treated waste water fulfills a defined conditions of turbidity it passes through the reverse osmosis treatment and then through the UV reactor. The recovered mud will enter the bio digester in order to produce the methane which will be transformed to energy (heat or electricity). That energy can be valorized for the running of the treatment station. We will present in this section results from applying the equations and formulas developed above for every compartment alone.

\subsection{For the reverse osmosis compartment}

The final equations were analyzed and resolved analytically. Firstly, we have estimated the evolution of the electric field and magnetic field as function of the position through the membrane for the sodium ion.

Secondly, we have estimated the evolution of the electric field for different incidence angles and as function of the positions through the membrane for the sodium ion.

Figure $n^{\circ} 1$ presents the evolution of the electric field through the membrane for the incident wave describing to the sodium ion motion.

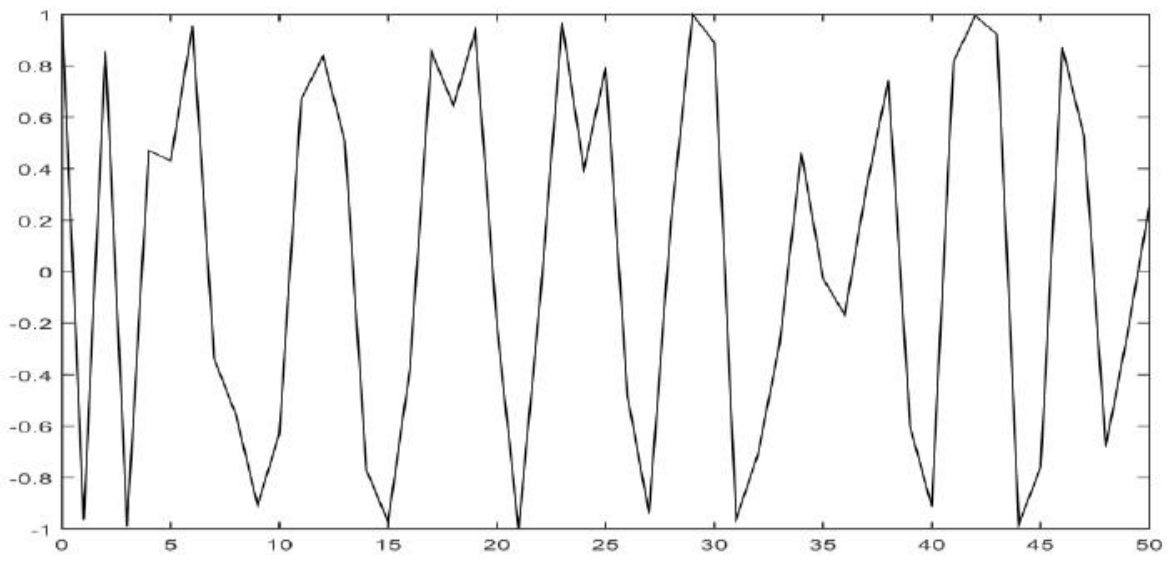

Position through the membrane (mm)

Fig.1: Evolution of the incident electric field through the membrane 
The variation of the magnetic field as function of the depth through the membrane for the incident wave representing the sodium ion in its displacement is in figure 2.

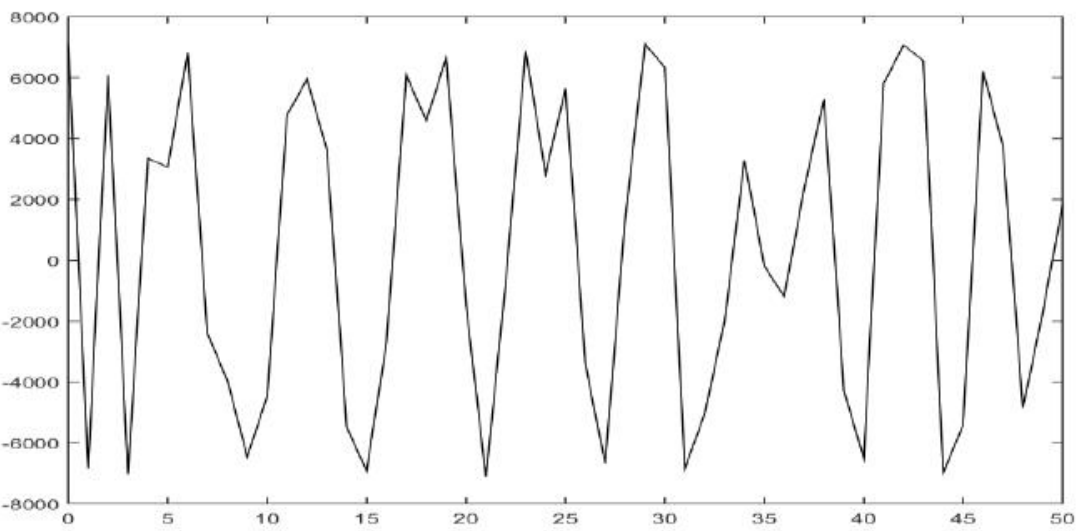

Position through the membrane (mm)

Fig.2: Evolution of the incident magnetic field through the membrane

For both, the electric and magnetic incident fields, we can see clearly that the global trends depend on the position inside the membrane. Also amplitudes and distances between successive extremes vary through the membrane. These findings clearly show the influence of the membrane structure and texture. Then we can consider the modeling approach as a tool to diagnose the membrane state and to test its efficiency. In fact, we have considered in this work every particle in the wastewater in it displacement as a wave that interacts and interferes with other waves (particles) and with filtering membrane. The most efficient membrane is the one through which the interference intensity is minimal. The modeling approach proposed here permits to evaluate this phenomenon by considering the membrane structure and texture.

\subsection{For the UV reactor compartment}

Figure 3 and figure 4 present, respectively, the resulting radial profiles and the local volumetric rate of energy absorbed (LVREA) inside an open channel photo reactor containing wastewater

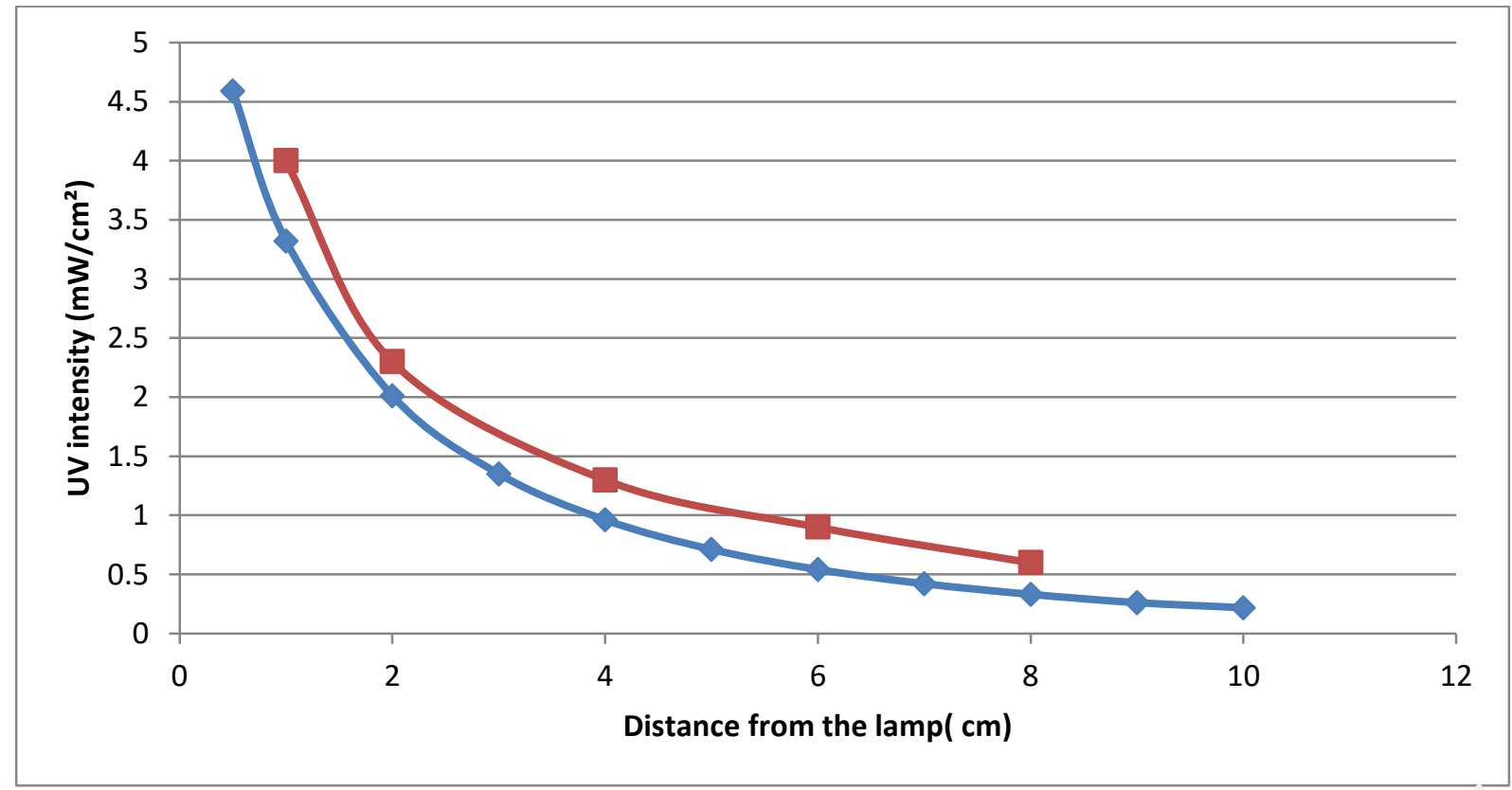

Fig.3: Radial profiles of the incident $U V$ radiation energy density (Theoretical values Experimental values 


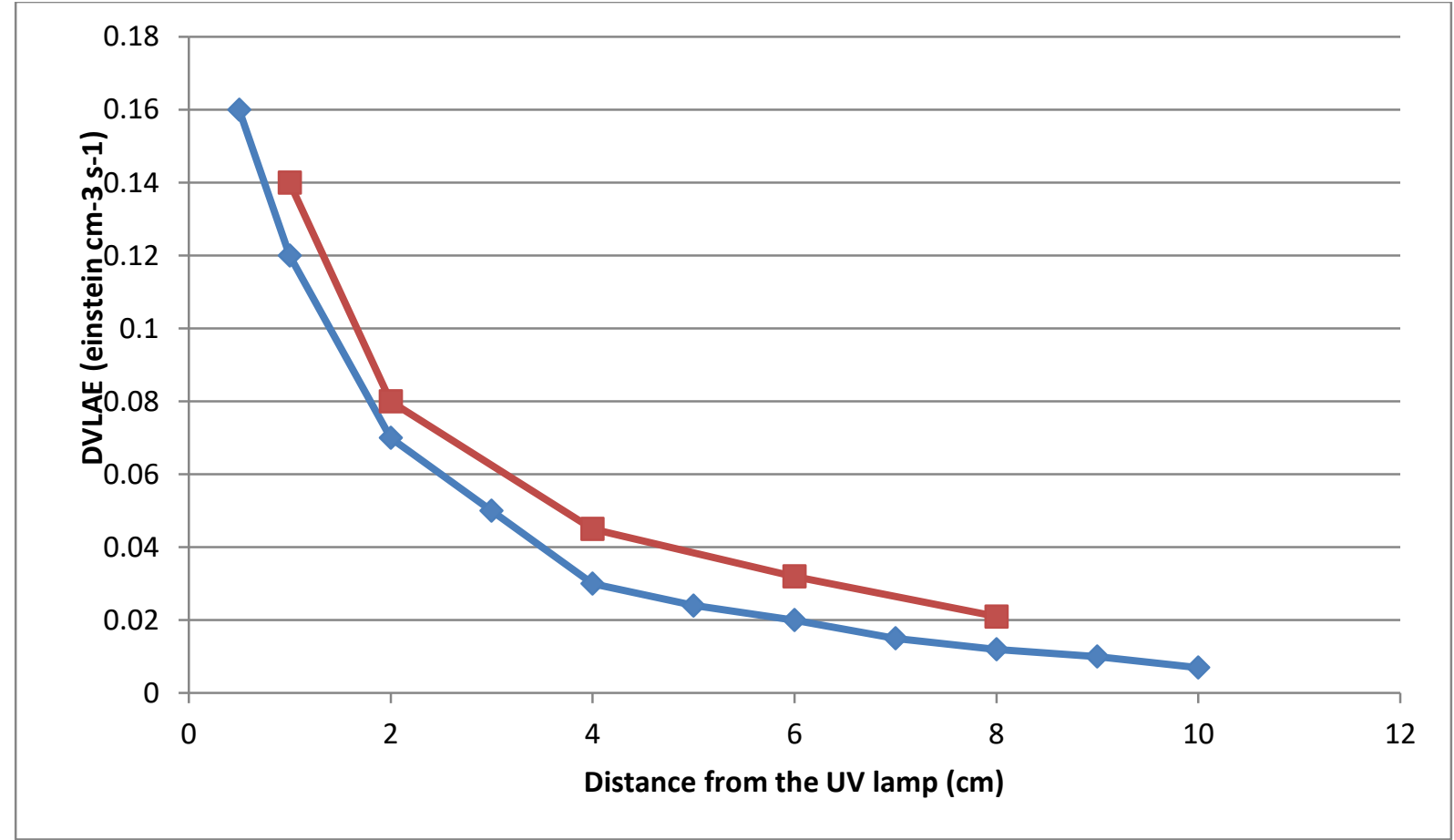

Fig.4: Radial profiles of the LVREA (Theoretical values , Experimental values $\square$

For figure 3, we can say that increasing the radial distance, the value of $(\varphi)$ decreases because we are moving away from the radiation source. However, it is interesting to notice that the curve goes through a maximum. This is the result of in-scattering contributions in the region closer to the inner reactor wall where intensities have their maximum values. From that point on, geometric effects supersede the influence of in-scattering, and the incident radiation decreases thereafter. When the particle concentration (bacteria) is increased, this phenomenon becomes more important. At both ends of the reactor, this profile shows a continuous and important decrease. This result is not related to the reactor performance; it is just the direct effect of the boundary condition (Sellami et al 2003, Sellami et al 2019).

For figure 4, we can see that the absorbed energy is maximal for the highest bacteria concentration and absorption is almost complete at the end of the reactor. Radial profiles indicate a strong absorption for low values of $r$. However, the maximum absorption is not observed at $r=0$. This behaviour should be attributed to the presence of a concentrated boundary condition in a narrow field of directions. In fact, at the reactor top position, this profile seems to represent just an exponential decay. When changing the location of the radial profile, the main difference in the reactor is that contributions from the lamp volume of irradiation become increasingly smaller.

\subsection{For the biogas digester compartment}

Application was done in order to size a treatment station for a yeast industry installed in Tunisia (Sellami and Marzouk 2013). The debit of waste water issued is about $1500 \mathrm{~m}^{3} /$ day with a charge of about $10000 \mathrm{mg} / \mathrm{l}$ in unity of chemical demand in oxygen (CDO), $8871 \mathrm{mg} / \mathrm{l}$ in unity biochemical demand in oxygen in five days (BDO5), 886 $\mathrm{mg} / \mathrm{l}$ in unity of suspended matter and $486 \mathrm{mg} / \mathrm{l}$ in unity of nitrogen. Annually we can reach a charge of about $5612970 \mathrm{~kg}$ for the chemical demand in oxygen and a charge of about $4856872,5 \mathrm{~kg}$ for the biochemical demand of oxygen.

We have calculated the hydraulic characteristics of the biogas digester, its physical parameters, the energy produced and its thermo-economic function. The following tables recapitulate our results. 
International Journal of Environment, Agriculture and Biotechnology, 5(3)

May-Jun, 2020 / Available: https://ijeab.com/

Table .1: Hydraulic characteristics, physical parameters and biogas produced

\begin{tabular}{|l|l|}
\hline debit of the effluent $\mathrm{Q}, \mathrm{m}^{3} / \mathrm{h}$ & 1500 \\
\hline velocity of the ascendant flux $\mathrm{V}, \mathrm{m} / \mathrm{h}$ & 0,55 \\
\hline surface of the transversal section of the digester $\mathrm{A}, \mathrm{m}^{2}$ & $\mathbf{1 1 3 , 1 3}$ \\
\hline Length of the surface, $\mathrm{m}$ & 13 \\
\hline Width of the surface, $\mathrm{m}$ & 9 \\
\hline Total volume of the liquid in the reactor $\mathrm{V}_{\mathrm{L}}, \mathrm{m}^{3}$ & 905 \\
\hline Height of the reactor $\mathrm{H}_{\mathrm{L}}, \mathrm{m}$ & $\mathbf{8}$ \\
\hline Height for the collect and the storage of the biogas $\mathrm{H}_{\mathrm{G}}, \mathrm{m}$ & 2,5 \\
\hline Total height of the reactor $\mathrm{H}_{\mathrm{T}}, \mathrm{m}$ & $\mathbf{1 0 , 5}$ \\
\hline Hydraulic retention time $\mathrm{HRT}, \mathrm{h}$ & 14,5 \\
\hline Time of rest $\mathrm{TR}$, Day & 4 \\
\hline MES concentration in the biomasse zone $\mathrm{X}_{\mathrm{MES}}, \mathrm{Kg} / \mathrm{m}^{3}$ & 2,7 \\
\hline Amount of sludge produced $\mathbf{P x}, \mathrm{MEs}, \mathrm{Kg} /$ day & 3082 \\
\hline Amount of methane produced, $\mathrm{m}^{3} /$ day & 3877 \\
\hline Energyproduced, KJ/day & $123,27.10^{6}$ \\
\hline Amount of CaCO & 1950 \\
\hline
\end{tabular}

Table. 2: Results from thermo economic analysis

\begin{tabular}{|c|c|}
\hline Valorisable energyGWh/year & 13 \\
\hline Energy for digester heating, GWh/year & 4,34 \\
\hline Energy for pumping $\mathrm{GWh} /$ year & 0,02 \\
\hline Energy disponible, GWh/year & 8,64 \\
\hline Electrical energy produced GWh/year & 2,6 \\
\hline Designation & Cost DN \\
\hline Installation (material, work force... & 30413 \\
\hline Equipment & 87660 \\
\hline Total & 118073 \\
\hline Diverse unexpected $(15 \%)$ & 17710 \\
\hline Somme & 133494 \\
\hline Yearly valorized energy & 13 GWhyearly \\
\hline Yearly gain of energy after considering the energy consumption & 8.64 GWhyearly \\
\hline Yearly Electrical energy produced & 2,6 GWhyearly \\
\hline Power of the motor $(\mathrm{KW})$ & 356 \\
\hline Cost of the motor (DT) & 1254000 \\
\hline Cost of functioning DT/an & 364000 DT/an \\
\hline Annual gain (DT/year) & 119600 \\
\hline Compensation time without subvention & 10 ans et 6 mois. \\
\hline Compensation time with a subvention of 30 to $40 \%$ & 6 ans et 4 mois \\
\hline
\end{tabular}


The system we are conceptualizing in order to cogenerate electricity and heat from the biogas produced after treating the waste water issued from yeast industry is formed from three important parts: biogas collector (gas-liquid-solid separator, dropping network), tank of sludge, alimentation system.

The thermo economic evaluation (Erlach et al 1999) of the biogas produced from the two stations shows that we can realize a gain of about 119600 DT/year for the yeast industry with a compensation time of the cost of reactor installation between 6 and 10 years.

\section{CONCLUSION}

We have detailed in this work a modeling approach that permits to conceptualize a wastewater treatment plant to valorize the wastewater. The plant is equipped with three advanced treatment techniques: a reverse osmosis unit, a UV reactor and a biogas digester. We have presented the necessary equations to conceptualize every device and to size it. For every part of the model physics analysis was detailed and results from theoretical calculus were given. An application to valorize the biomass extracted from the wastewater issued from a yeast industry was done. This valorization consists in producing energy from the methane recovered and in using that energy in the running of all the plant. A thermo-economic analysis was done. We can say that we can realize a gain of about 119600 DT/year for the yeast industry from the energy produced with a compensation time of the cost of reactor installation between 6 and 10 years.

\section{REFERENCES}

[1] Abdennaceur.H, Mahrouk.M, Ouzari.H, Cherif.M, Boudabous.A, Damelincourt.J.J 2000. "UV disinfection of treated waste water in a large-scale pilot plant and inctivation of selected bacteria in a laboratory UV device". Bioresource Technology. 2000; 0000.p.1-10

[2] Alfano.O.M.,Romero.R.L., Cassano.A.E. Radiation field modelling in photoreactors-.II.Heterogeneous media.Chemical Engineering Science. 1986, 41(5).p. $1137-$ 1153

[3] Arsova L. 2010 "Anaerobic digestion of food waste: Current status, problems and an alternative product" $S$. Degree in Earth Resources Engineering Department of Earth and Environmental EngineeringFu Foundation of Engineering and Applied Science Columbia University, 77 pages

[4] Azimi A.A. and Zamanzadeh M. 2004."Determination of design criteria for UASB reactors as a wastewater pretreatment system in tropical small communities" Int. J. Environ. Sci. Tech. Vol. 1, No. 1, pp. 51-57, Spring 2004
[5] Banu J.R., Kaliappan S. and Yeom I.T 2007 "Treatment of domestic wastewater using upflow anaerobicsludge blanket reactor"Int. J. Environ. Sci. Tech., 4 (3): 363-370, 2007

[6] Duncan .M 2004"Domestic Wastewater Treatment in Developing Countries" First published by Earthscan in the UK and USA in 2004 Copyright (c) Duncan Mara, 2003 ISBN: 1-84407-019-0

[7] Elmissaoui, Sellami M H, Othmen T. "A modeling approach based on electromagnetic wave analogy to ameliorate the efficiency of filtering membrane techniques for water treatment" Submitted 2020.

[8] Erlach B., Serra L., and Valero A. 1999. "Structural theory as standard for thermoeconomics". Energy Conversion and Management 40, 1627-1649.

[9] Gasparikova E. S. Kapusta, I. Bodík, J. Derco, and K. Kratochvll, 2005" Evaluation of Anaerobic-Aerobic Wastewater Treatment Plant Operations", Polish Journal of Environmental Studies Vol. 14, No.1 pp 29-32, 2005

[10] Haralambos M. 1998 "Analogy between the Navier-Stokes equations and Maxwell's equations: Application to turbulence Physics of Fluids (1994-present) 10, 1428 (1998); doi: 10.1063/1.869762 View online: http://dx.doi.org/10.1063/1.869762

[11] Hiroyuki T.2001 «Maxwell Theory from Matrix Model" Nucl.Phys.Proc.Suppl. 94 (2001) 718-721

[12] Karine C., Renaud C., and David R.2017 Models, structure, and generality in Clerk Maxwell's theory of electromagnetism The Oxford Handbook of Generality in Mathematics and the Sciences DOI 10.1093/oxfordhb/9780198777267.013.1

[13] Kiselyov K. , Shestakov. K, Horohorina I, Abonosimov O and Lazarev S, 2019 "Modelling of substance interactions in electrochemical membrane processes by basis of the friction theory", Journal of Physics: Conference Series, 10.1088/1742 6596/1278/1/012020, 1278, (012020).

[14] Kozlovaa A.A., Trubyanovb M.M, Atlaskinb A.A., Yanbikovb N.R., and Shalygina M.G. 2019 "Modeling Membrane Gas Separation in the Aspen Plus Environment" ISSN 2517-7516, Membranes and Membrane Technologies, 2019, Vol. 1, No. 1, pp. 1-5. () Pleiades Publishing, Ltd.

[15] Lettinga, G., and Hulshoff Pol, L.W. 1991 "UASB process design for various types of wastewater", Water Science \& Technology, Vol. 24, No. 8, 1991, pp. 87-107.

[16] Lew B., Tarre S., M. Belavski and M. Green 2004 “ UASB reactor for domestic wastewater treatment at low temperatures: a comparison between a classical UASB and hybrid UASB-filter reactor" Water Science and Technology Vol 49 No 11-12 pp 295-301 (C) IWA Publishing 2004

[17] Lise Appels, Jan Baeyens, Jan Degre've , RafDewil 2008 ‘ Principles and potential of the anaerobic digestion of wasteactivated sludge" Progress in Energy and Combustion Science 34 (2008) 755-781

[18] Lopez Ariste.A and Semel.M.1999 "Analytical solution of the radiative transfer equation for polarized light”.Astronomy and astrophysics.1999; 350.p.1089-1099.

[19] Mogens H., Markvan L., George E. and Damiro B. 2008 “ Biological waste water treatment. Principles, modelling and 
design" Book published by IWA Publishing, London, Cambridge University Press, 449 pages.

[20] Moreno.B, Goni.F, Fernandez.O, Martinez.J.A, Astigarraga.M. 1997"The disinfection of wastewater by Ultraviolet light”.Wat. Sci. Tech. 1997; 35(11-12).p. 233235.

[21] Santarelli.F. 1983 “One dimentional radiative transfer in planar participating media “.Lat.Am.J.Heat mass transf. 1983; 7,p.35-49.

[22] Sellami M.H, Abdennaceur H. and Sifaoui M.S 2003"Modelling of UV radiation field inside a photoreactor designed for wastewater disinfection Experimental validation" Journal of Quantitative Spectroscopy and Radiative TransferVolume 78, Issues 3-4, (2003) Pages 269287

[23] Sellami MH and Marzouk H 2013 “A Thermo-Economic Modeling to Conceptualize a Biogas Digester Destined to Energetic Valorization of Waste Water under Products," International Journal of Renewable Energy \& Biofuels, Vol. 2013 (2013), Article ID 563795, DOI: 10.5171/2013.563795

[24] Sellami MH 2015 “ Hydraulique: De la théorie à l'application. Hydraulique Agricole: Mise en équation, conception et dimensionnement » EdLivre, France, ISBN: 978-2-332-98572-9 142 pages

[25] Sellami MH, Adbennaceur H., Ghoul I et Boughdir A 2019 «Approche de modélisation pour la conception des réacteurs UV de traitement des eaux usées' Journal International Sciences et Techniques de l'Eau, $\mathrm{N}^{\circ} 1$ Vol. IV, 2019, ISSN 17376688

[26] Tosa K. and Hirata.T. 1999 "Photoreactivation of enterohemorrhagicescherichia coli following UV disinfection".Wat.Res. 1999; 33(2).p. 361-366.

[27] Venkatesh K.R, Rajendran M. and Murugappan A. 2013 “ Start-Up Of An Upflow Anaerobic Sludge Blanket Reactor Treating Low-Strength Wastewater Inoculated With NonGranular Sludge" International Refereed Journal of Engineering and Science, 2(1).p. PP.46-53 